\section{Osteoclastic giant cell variant of urothelial carcinoma in a COVID- positive patient: A rare variant in an} unusual circumstances

\author{
Chanchal Rana $^{1 *}$, Divya Goel ${ }^{2}$, Akanksha Singh $^{3}$, Suresh Babu ${ }^{4}$ \\ and Vishwajeet Singh ${ }^{5}$
}

\begin{abstract}
${ }^{1}$ Associate Professor, Department of Pathology, King George's Medical University, Lucknow, UP, India

${ }^{2}$ Professor, Department of Pathology, King George's Medical University, Lucknow, UP, India ${ }^{3}$ Senior Resident, Department of Pathology, King George's Medical University, Lucknow, UP, India ${ }^{4}$ Professor, Department of Pathology, King George's Medical University, Lucknow, UP, India ${ }^{5}$ Professor, Department of Urology, King George's Medical University, Lucknow, UP, India
\end{abstract}

\section{Abstract}

Bladder carcinomas have a great propensity for divergent differentiation with more that $90 \%$ being Transitional cell carcinoma. Several histological variants have been have described so far; they are not only morphologically unique but also have significant prognostic and therapeutic differences making their timely identification of paramount importance. Osteoclastic giant cell variant of urothelial carcinoma is very rare type with controversial management. Studies from China have documented higher incidence and severity of illness in COVID-19 positive cancer patients. We report an unusual case of Osteoclastic giant cell variant of urothelial carcinoma in a 63 yrs old male patient associated with simultaneous COVID-19 infection.
More Information

*Address for Correspondence: Dr. Chanchal Rana, Associate Professor, Department of Pathology, King George's Medical University, Lucknow, UP, India, Email: chanchal11aug@yahoo.com

Submitted: February 21, 2021

Approved: April 12, 2021

Published: April 13, 2021

How to cite this article: Rana C, Goel D, Singh A, Babu S, Singh V. Osteoclastic giant cell variant of urothelial carcinoma in a COVIDpositive patient: A rare variant in an unusual circumstances. Arch Case Rep. 2021; 5 : 009-011.

\section{DOI: 10.29328/journal.acr.1001047}

Copyright: @ 2021 Rana C, et al. This is an open access article distributed under the Creative Commons Attribution License, which permits unrestricted use, distribution, and reproduction in any medium, provided the original work is properly cited.

Keywords: Osetoclastic giant cell; Variant; Urinary bladder; COVID-19

Check for updates

OPEN ACCESS

\section{Introduction}

Bladder carcinomas have a great propensity for divergent differentiation although $>90 \%$ arise from transitional epithelium [1]. Squamous and glandular variants are most common, however several other variant have also been described so far and have been included on 2004 and 2016 WHO classification of tumors of urinary bladder. Osteoclast rich undifferentiated carcinoma of the urinary tract was described first in 2006 by Baydar, et al. as an aggressive variant common in elderly males [2]. Since then only $\sim 30$ cases have been reported so far with none from India [2-5].

The ongoing COVID-19 pandemic caused by severe acute respiratory syndrome corona virus 2 (SARS-CoV-2) have greatly impacted the health services worldwide challenging the way modern medicine has been practiced for decades. Studies from china have documented higher incidence and severity of illness in COVID-19 positive cancer patients [3,4]. So the present case is unusual being a rare variant but also unique due to its association with a COVID-19 positive patient.
Histological variants are morphologically unique and have significant prognostic and therapeutic differences making their timely identification of paramount importance. Also due to the rarity, the appropriate treatment of this variant is controversial which has been further complicated by, in this case, guidelines and management issues in ongoing COVID-19 pandemic.

\section{Case report}

A 63 year old male who was a known case of hypertension, hypertrophic cardiomyopathy and asthma; presented with complain of sudden onset intermittent gross hematuria for 10 days. As an institutional protocol the patient underwent RTPCR based COVID testing before outpatient department (OPD) consultation and was reported negative. Ultrasonography (USG) was then performed which revealed a hypo-echoicsoft tissue mass measuring $3.2 \times 2.6 \mathrm{cms}$, arising from the right poster-lateral aspect of urinary bladder. On Contrast Enhanced Computerized Tomography (CECT) an early peri-vescical extension of the above mentioned mass was 
also identified. Hematological and biochemical evaluation were largely unremarkable. After proper counseling and consent transurethral resection of bladder tumor (TURBT) was planned under general anesthesia with proper protocol pertaining to COVID pandemic. The patient was again tested for COVID-19 before the commencement of procedure. Complete resection of mass was performed and the specimen was sent for histopathological evaluation.

Histopathological evaluation revealed a high grade tumor displaying a neoplasm composed of a mixture of mononuclear malignant epithelial cells and multinucleated osteoclast-like reactive giant cells with a rich vascular network (Figure 1a). High grade papillary urothelial carcinoma was also identified in the adjacent area (Figure 1b). Lamina and muscle invasion were also seen. On immunohistochemical analysis, the osteoclastic giant cells were positive for CD68 and negative for CK20 and desmin (Figure 1c). The high grade classical papillary urothelial carcinoma component showed diffuse cytoplasmic membranous positivity for CK20 (Figure 1d). The mononuclear component did not expressed cytokeratin, epithelial membrane antigen and P53.

Chemotherapy has been was planned; however the patient was detected COVID-19 positive when the testing was performed as a part of protocol before the commencement of chemotherapy. The patient had mild symptoms during the course and again tested negative after a week. Presently he is stable and in follow up.

\section{Discussion}

Giant cell morphology can be encountered in urothelial

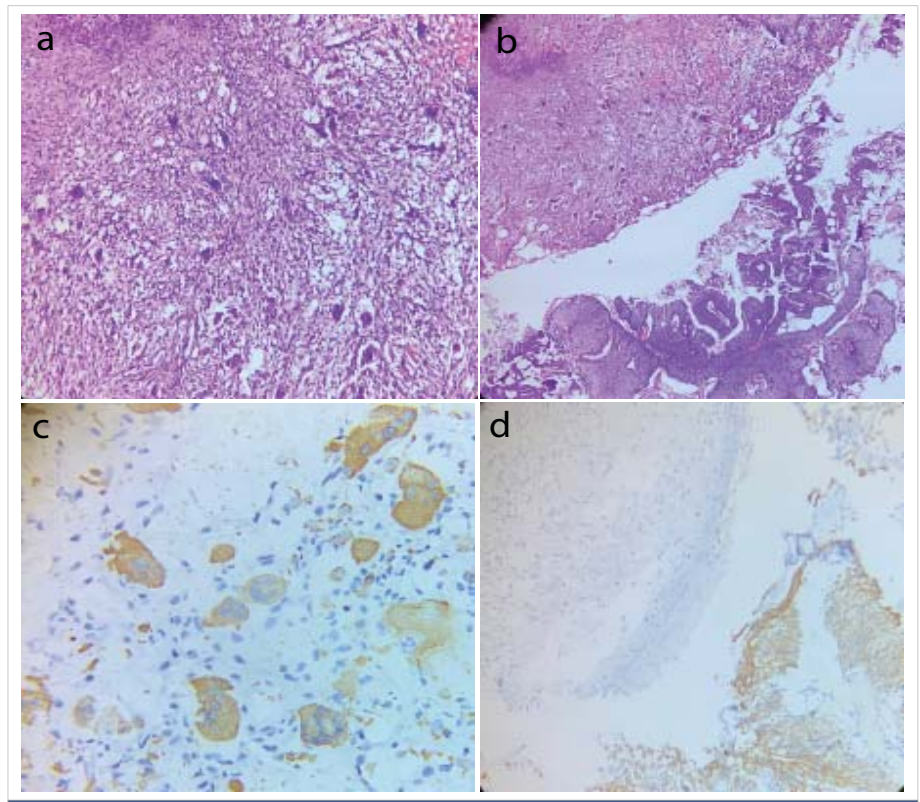

Figure 1: Case of osteoblastic variant of bladder carcinoma displaying (a) Area rich in osteoblast like giant cells with intervening round to spindle shaped mononuclear cells (Hematoxylin and eosin stain, 400x); (b) Adjacent area of conventional high grade papillary urothelial carcinoma (Hematoxylin and eosin stain, 200x); (c) CD68 positivity in giant cell component and; (d) CK20 membranous positivity in conventional urothelial carcinoma component with absence of giant cell component. tumors in certain scenario like: sarcomatoid carcinomas with sarcomatous spindle cell giant cells, syncytio-trophoblast giant cells in high grade tumors, pleomorphic giant cell carcinomas, chorocarcinoma etc [2]. Osteoclastic type giant cell tumors (OGC) are more commonly found in skeletal system, soft tissues, pancreas, gall bladder and breast $[2,5,6]$. Their existence is very rarely encountered in urinary tract, such that approximately 30 cases in urinary bladder have been reported so far, with first case been described in 1983 by Kimura, et al. [7], however later Bayer et al named this entity Osteoblastic rich undifferentiated carcinoma or urinary tract and documented the largest case series of six cases [2].

Majority of OGC urinary bladder have been encountered in elderly male patients ( $7^{\text {th }}$ decade or older) with few cases in younger age group ( $<40 \mathrm{yrs}$ ) [2]. Our patient was also a male and 63 years of age who presented with sudden onset painless gross hematuria, which is typical for urothelial neoplasms. Other complaints like dysuria and pain may also be encountered. OGC urinary bladder recapitulate the morphology of its counterpart in skeletal and soft tissue system, comprising of mild to moderately pleomorphic mononuclear (spindle to round/oval) cells and cytologically bland osteoclast like giant cells which are scattered uniformly among the mononuclear cells. In contrast to the soft tissue and skeletal OGC tumors, which are slow growing relatively indolent tumors, those occurring in urinary bladder are aggressive tumor usually diagnosed at an advanced stage and have poor prognosis.

Baydar, et al. have documented presence of carcinoma in situ or high grade papillary urothelial carcinoma in adjacent urothelium in all of their cases, which is in accordance with our findings. On immunohistochemistry, giant cells are known to express CD68, alpha 1 antitrypsin, acid phosphatase, vimentin, CD51 and CD54. Cytokeratin and epithelial membrane antigen may be expressed by mononuclear cells in a patch or diffuse fashion in approximately one third of cases, with absence in osteoclastic giant cells [2]. P53 mutational alteration is recognized as the leading genetic abnormality in development of high grade urothelial neoplasm with p53 immunohistochemical expression documented in $27.2 \%$ $66 \%$ of urothelial carcinoma and can have a potential role on osteoblastic giant cell transformation [8-10]. Studies have shown p53 positivity in both mononuclear cells and accompanying urothelial neoplasm suggesting the malignant nature of mononuclear cells. Bayer et al observed p53 expression in half of their cases. Absence of pleomorphism, mitotic activity, and p53 and ki 67 expressions in giant cells suggests their non neoplastic nature, further confirming OGC urothelial carcinoma as an osteoclast rich undifferentiated urothelial carcinoma. In our cases the mononuclear cells did not expressed cytokeratin, epithelial membrane antigen of p53 positivity.

Studies from china have documented higher incidence and 
severity of illness in COVID-19 positive cancer patients [3,4]. Fortunately, in this case the patient developed COVID-19 infection with mild symptoms even in the presence of other co morbidities like hypertrophic cardiomyopathy and asthma. Under general circumstances the standardized approach for muscle invasive bladder cancer in patients with adequate fitness for therapy, includes neoadjuvant chemotherapy (NAC) followed by radical cystectomy (RC) and an extended lymph node dissection. In addition, trimodality therapy (TMT) including maximal transurethral resection of bladder tumor (TURBT) followed by combined chemotherapy and radiotherapy (RT) may be appropriate for select patients. Determination of TMT versus NAC followed by surgical resection is often dictated by patient health, frailty, and preferences [11].

COVID-19 pandemic has not only greatly impacted the health service infrastructure worldwide but had also markedly influenced the treatment and management guidelines. NHS England guidelines written in response to the extreme threat posed by COVID-19 advise the categorization of cancer treatments according to the intent and risk-benefit ratio $[11,12]$. They also advocate considering less resourceintensive regimens, accounting for other patient risk factors such as age, cardiac and chest disease, offering treatmentbreaks where appropriate, using growth factors to reduce neutropenia and prescribing hypofractionated radiotherapy regimens where possible [13]. Radical cystectomyis still considered a valid option for younger patients and the use of neo adjuvant therapy should be discouraged due to potential long period of immunosuppression [11]. However in the present situation, the risks are substantialfor older, less fit patients who often have significant co morbiditiesand a high risk of death from hospital acquired COVID-19.

\section{References}

1. Samaratunga $H$, Delahunt $B$. Recently described and unusual variants of urothelial carcinoma of the urinary bladder. Pathology (Phila). 2012; 44: 407-418.

PubMed: https://pubmed.ncbi.nlm.nih.gov/22777074/

2. Baydar D, Amin MB, Epstein Jl. Osteoclast-rich undifferentiated carcinomas of the urinary tract. Mod Pathol. 2006; 19: 161-171. PubMed: https://pubmed.ncbi.nlm.nih.gov/16322750/

3. Liang W, Guan W, Chen R, Wang W, Li J, et al. Cancer patients in SARS-CoV-2 infection: a nationwide analysis in China. Lancet Oncol. 2020; 21: 335-337.

PubMed: https://pubmed.ncbi.nlm.nih.gov/32066541/

4. Wang D, Hu B, Hu C, Zhu F, Liu X, et al. Clinical Characteristics of 138 Hospitalized Patients With 2019 Novel Coronavirus-Infected Pneumonia in Wuhan, China. JAMA. 2020; 323: 1061-1069. PubMed: https://pubmed.ncbi.nIm.nih.gov/32031570/

5. Osman C, Muammer B, Murat O, Tamer A, Fatih A. Osteoclast-type giant cell carcinoma of the urinary bladder: An unusual and aggressive variant of urothelial carcinoma. Urol Case Rep. 2019; 23: 50-51. PubMed: https://pubmed.ncbi.nlm.nih.gov/30581755/

6. Akatsu T, Kameyama K, Kawachi S, Tanabe M, Aiura K, et al Gallbladder carcinoma with osteoclast-like giant cells. J Gastroenterol. 2006; 41: 83-87.

PubMed: https://pubmed.ncbi.nlm.nih.gov/16501862/

7. Kimura K, Ohnishi $\mathrm{Y}$, Morishita H, Amezaki M, Irikura H. Giant cell tumor of the kidney. Virchows Arch A Pathol Anat Histopathol. 1983; 398: 357-365

PubMed: https://pubmed.ncbi.nlm.nih.gov/6402846/

8. Oda Y, Sakamoto A, Saito T, Matsuda S, Tanaka K, et al. Secondary malignant giant-cell tumour of bone: molecular abnormalities of p53 and $\mathrm{H}$-ras gene correlated with malignant transformation. Histopathology. 2001; 39: 629-637.

PubMed: https://pubmed.ncbi.nlm.nih.gov/11903582/

9. Genega EM, Hutchinson B, Reuter VE, Gaudin PB. Immunophenotype of high-grade prostatic adenocarcinoma and urothelial carcinoma. Mod Pathol 2000; 13: 1186-1191.

PubMed: https://pubmed.ncbi.nlm.nih.gov/11106075/

10. Kelsey KT, Hirao T, Schned A, Hirao S, Devi-Ashok T, et al. A populationbased study of immunohistochemical detection of p53 alteration in bladder cancer. $\mathrm{Br} \mathrm{J}$ Cancer 2004; 90: 1572-1576. PubMed: https://pubmed.ncbi.nlm.nih.gov/15083187/

11. Patel K, Choudhury A, Hoskin P, Varughese M, James N, et al. Clinical Guidance for the Management of Patients with Urothelial Cancers During the COVID-19Pandemic-Rapid Review. Clin Oncol. 2020; 32: 347-353. PubMed: https://pubmed.ncbi.nlm.nih.gov/32389318/

12. Liu C, Zhao Y, Okwan-Duodu D, Basho R, Cui X. COVID-19 in cancer patients: risk, clinical features, and management. Cancer Biol Med. 2020; 17: 519-527.

PubMed: https://pubmed.ncbi.nlm.nih.gov/32944387/

13. Barcellini A, Filippi AR, Dal Mas F, Cobianchi L, Corvò R, et al. To a new normal in radiation oncology: looking back and planning forward. Tumori. 2020; 106: 440-444.

PubMed: https://pubmed.ncbi.nlm.nih.gov/33045932/ 